\title{
The freshwater shrimp Atyaephyra desmarestii (Millet, 1831) as a bioindicator of hypoxic event effects on temperate freshwater systems
}

González-Ortegón, Enrique, Rodríguez, Antonio and Drake, Pilar

Instituto de Ciencias Marinas de Andalucía, CSIC, Avenida República Saharaui, 2, 11519 Puerto Real, Cádiz, Spain.

Phone: +34 95683612;

Fax: +34 956834701;

e-mail:quique.gonzalez@icman.csic.es 


\section{Abstract}

2 In order to assess the suitability of Atyaephyra desmarestii as a bioindicator of the effects of 3 hypoxic events on temperate freshwater systems, we investigated the respiratory responses of this 4 shrimp to increasing temperatures and progressive hypoxia at 2 different salinities. This study, 5 based on laboratory measurements, clearly demonstrates that this species has a moderate to poor 6 oxygen regulatory ability and a high sensitivity to hypoxia. The respiratory response of the shrimp 7 to increasing temperatures with increasing $\mathrm{M}_{\mathrm{O} 2}$ (low thermal regulation in oxygen uptake) was

8 observed within a wide thermal range $\left(15\right.$ to $\left.30^{\circ} \mathrm{C}\right)$, although the species seems to be vulnerable to 9 temperatures above $25^{\circ} \mathrm{C}$ in brackish water. This species copes best with hypoxia in brackish 10 water but only at low to moderate temperatures $\left(\mathrm{T} \leq 20^{\circ} \mathrm{C}\right)$. In freshwater, its habitual habitat, the 11 ability of $A$. desmarestii to oxyregulate seems to be less temperature dependent. These features

12 suggest that the respiratory response of $A$. desmarestii could be used in short term stress bioassays

13 to test the consequences of climate change and pollution events which lead to increased hypoxia of 14 aquatic habitats.

\section{Keywords}

16 Atyaephyra desmarestii, hypoxia, model species, bioindicator, oxyregulation, 17 oxygen consumption

\section{Introduction}

18 Hypoxic and anoxic events in aquatic systems have increased worldwide as a 19 result of climate change (warming and altered precipitation patterns) and high 20 nutrient run-off from agriculture and urban sewages (eutrophication).

21 Freshwater habitats are prone to hypoxia and anoxia when temperatures increase 22 (Diaz and Breitburg, 2009). When coupled with organic matter inputs, these

23 increases in temperature can also accelerate the eutrophication process, which is

24 an oxygen demanding process (Diaz, 2001). Organic enrichment combined with

25 hypoxia typically engenders depauperate macrobenthic communities (Rakocinski,

26 2012). In addition, changes in rainfall patterns and reduced freshwater due to

27 human use are expanding the boundaries of the brackish water realm, which is

28 characterized by lower oxygen solubility than freshwater.

Although warmer waters may reduce hypoxic thresholds in aquatic

30 organisms (Vaquer-Sunyer and Duarte, 2011), most species can maintain

31 adequate oxygen uptakes at dissolved oxygen concentrations (DO) above $5 \mathrm{mg}^{-1}$

32 (Vaquer-Sunyer and Duarte, 2008; Diaz and Breitburg, 2009). Crustaceans are

33 among the most sensitive aquatic taxa to hypoxia, as $50 \%$ of studied species show 
34 sublethal effects at a DO below $3.2 \mathrm{mg} \mathrm{l}^{-1}$ (Vaquer-Sunyer and Duarte, 2008,

35 2011). When the DO drops below this optimum level, many species require

36 physiological and behavioural adaptations to maintain satisfactory oxygen uptake

37 rates (Bridges and Brand, 1980; Wannamaker and Rice, 2000; Salvato et al.,

38 2001; Bernatis et al., 2007). However, these adaptations can be energetically

39 expensive, reducing the energy available for growth and reproduction (Das and

40 Stickle, 1994), or even insufficient (below a hypoxic threshold), since the

41 respiratory rates of the organisms become more dependent on the external DO

42 (Bridges and Brand, 1980; Hicks and McMahon, 2002). Organisms exposed to

43 hypoxic conditions are also less tolerant to environmental stresses (food

44 limitations, thermal stress, pollutants) than those exposed to normoxic water

45 (Cairns et al., 1975; Shimps et al., 2005; Paschke et al., 2010; Vaquer-Sunyer and

46 Duarte, 2011). Therefore, evaluating respiration rates and their dependence on DO

47 could be a very appropriate way of determining the potential effects of warming

48 and eutrophication on aquatic communities (Fränzle, 2006).

49 Freshwater shrimp are easy to culture and are highly sensitivity to

50 pollutants, which makes them useful organisms for biomonitoring programs.

51 Atyaephyra desmarestii, which is present in both lotic and lentic habitats, is the

52 species with the widest geographical distribution among the three freshwater

53 shrimps of the Iberian Peninsula (García-Múñoz et al., 2009). A. desmarestii is a

54 large detritivore and herbivore crustacean, which plays an important role in the

55 food web of freshwater habitats (García-Berthou and Moreno-Amich, 2000). Due

56 to its sensitivity to mine acid drainage and metals, it is considered a valuable

57 model species in short term stress bioassays (Janssens de Bisthoven et al., 2006;

58 Pestana et al., 2007). A. desmarestii is relatively tolerant to changes in

59 temperature and to a lesser extent in salinity; however, it generally inhabits well 
60 oxygenated waters, which suggests that the species is sensitive to low DO. In this

61 study, the respiratory responses to increasing temperature (warming effects) and

62 progressive hypoxia (eutrophication effects) were examined in a population from

63 southwestern Spain to assess whether A. desmarestii is an appropriate candidate

64 for testing the potential effects of climate change and pollution events on

65 temperate freshwater systems.

\section{2. Material and Methods}

\section{2.1. Shrimp collection and maintenance}

Specimens of $A$. desmarestii were collected by hand net from a tributary of

69 the Guadalete River (SW Spain) in November 2010. After a 24-h acclimation

70 period to aquariums, animals were transferred from the original water to aerated

71 freshwater (tap dechlorinated water) and brackish water (12 of salinity) obtained

72 by dilution of sea water. These salinities represent the boundaries of the salinity

73 range within which the species hyper-osmoregulate (unpublished data). For at

74 least 1 (freshwater) or 3 (brackish water) weeks prior to the experiments, shrimps

75 were maintained at a temperature of $20 \pm 1{ }^{\circ} \mathrm{C}$ under natural light and dark

76 conditions, and daily supplied with commercial dry flakes (TetraMin).

\section{2.2. Oxygen consumption measurements}

The oxygen consumption of individual shrimps was measured using

79 Strathkelvin 1302 polarographic electrodes connected to Strathkelvin 782 dual-

80 channel oxygen meter. Oxygen concentration versus time were recorded every 20

$81 \mathrm{~s}$ in a computer. Experiments were carried out during daytime, in black opaque

82 glass chambers of 8 to $20 \mathrm{ml}$, depending on shrimp sizes, which were maintained

83 at constant temperature $\left( \pm 0.1^{\circ} \mathrm{C}\right)$. Tested temperatures were $15,20,25$ and $30{ }^{\circ} \mathrm{C}$.

84 Although not significant differences were observed between short-term ( 1 to $2 \mathrm{~h}$ ) 
85 acclimated and non acclimated shrimps, individuals used in experiments at $30{ }^{\circ} \mathrm{C}$

86 remained exposed to this temperature during $1 \mathrm{~h}$ prior to respiratory measures.

87 Experimental salinities were produced using artificial seawater (Instant Ocean, 88 Aquarium Systems, Mentor, $\mathrm{OH}$ ). For each salinity-temperature combination, 18

89 to 25 shrimps were used. Mean ( \pm standard error) wet weights of shrimp used in 90 each salinity-temperature combination varied between $0.11 \pm 0.01\left(15^{\circ} \mathrm{C} ; 0.3\right.$ of

91 salinity) and $0.15 \pm 0.01 \mathrm{~g}\left(30{ }^{\circ} \mathrm{C} ; 0.3\right.$ salinity), whereas individual wet weights

92 did between 0.05 and $0.33 \mathrm{~g}( \pm 0.0001 \mathrm{~g})$.

\subsection{Data Analysis}

Specific oxygen consumption rates $\left(\mathrm{M}_{\mathrm{O} 2}\right)$ were estimated on the

95 continuous plots of DO versus time excluding the first ten minutes to avoid the 96 manipulation stress of shrimps. Short term oscillations were smoothed by fitting

97 measures to a third order polynomial curve (Figure 1). Smoothed values were 98 used to obtain mean $\mathrm{M}_{\mathrm{O} 2}$ values, as a function of DO grouped into $0.5 \mathrm{mg} \mathrm{O}_{2} \mathrm{l}^{-1}$ 99 intervals, for the whole range of DO covered by the experiment $\left(\approx 7\right.$ to $0.5 \mathrm{mg} \mathrm{O}_{2}$

$100 \mathrm{l}^{-1}$ ). Since absolute $\mathrm{M}_{\mathrm{O} 2}$ values were shrimp size-dependent, the oxyregulation 101 degree of each shrimp was estimated on the curve build with $\mathrm{M}_{\mathrm{O} 2}$ expressed on a 102 relative basis. For comparative purpose among the different temperature-salinity 103 combinations, the $\mathrm{M}_{\mathrm{O} 2}$ measured at $6 \mathrm{mg} \mathrm{l}^{-1}$ was considered to be equal to 100 and 104 the rest of specific rates were calculated relative to this reference value. In this 105 plot, completely oxygen-independent behaviour (constant $\mathrm{M}_{\mathrm{O} 2}$ irrespectively of 106 DO = oxyregulation) is expected to yield a horizontal straight line; completely 107 oxygen-dependent behaviour (oxyconformity), a straight line with a slope equal to 108 1; and partial oxygen dependence should yield curve, the curvature of which 109 depends on the degree of dependence (Figure 1). For each tested specimen, the 110 degree of oxyregulation with progressive hypoxia was assessed as a "percent $\mathrm{O}_{2}$ 
111 regulation" value (Hicks and McMahon, 2002). This value was computed as the

112 difference between the expected reduction in oxygen uptake for a total

113 oxyconform individual and the observed reduction (Figure 1). Namely, the degree

114 of oxyregulation was estimated at DO of $5 \mathrm{mg} \mathrm{l}^{-1}$ (well-oxygenated water), $3 \mathrm{mg} \mathrm{l}^{-}$

$115{ }^{1}$ ( $\approx$ hypoxic threshold for sublethal effects on crustaceans) and $1 \mathrm{mg} \mathrm{l}^{-1}$ (severe

116 hypoxia). For each shrimp, an overall oxyregulation was also estimated at DO

117 between 6 and $0.5 \mathrm{mg} \mathrm{l}^{-1}$.

118 Additionally, to test for differences in absolute $\mathrm{M}_{\mathrm{O} 2}$ values at the three

119 selected levels of DO $\left(5,3\right.$ and $\left.1 \mathrm{mg} \mathrm{O}_{2} \mathrm{l}^{-1}\right)$, prior to statistical analysis, effects of

120 shrimp sizes on their $\mathrm{M}_{\mathrm{O} 2}$ were overcame by adjusting them to those of $0.12 \mathrm{~g}$ wet

121 weight specimen using the corresponding (salinity-temperature) potential least-

122 squares regression between the $\mathrm{M}_{\mathrm{O} 2}\left(\mathrm{mg} \mathrm{O}_{2} \mathrm{~g}^{-1} \mathrm{~h}^{-1}\right)$ and the wet weight $(\mathrm{g})$ of 123 shrimps (Gónzalez-Ortegón et al., 2010). The $\mathrm{Q}_{10}$ between each pair of 124 temperatures differing in $5{ }^{\circ} \mathrm{C}\left(\mathrm{T}_{\mathrm{i}}\right.$ and $\left.\mathrm{T}_{\mathrm{j}}\right)$ was estimated as $\left(\mathrm{M}_{\mathrm{O} 2 \mathrm{j}} / \mathrm{M}_{\mathrm{O} 2 \mathrm{i}}\right)^{2}$.

125 Statistical differences in percent $\mathrm{O}_{2}$ regulation and absolute $\mathrm{M}_{\mathrm{O} 2}$ values at 126 each hypoxic level were tested by two-way ANOVAs (factors: salinity and 127 temperature). Since significant factor interaction existed, data sets were split by 128 temperatures and salinity to perform a further one-way (factor: temperature129 salinity interaction) ANOVA. Student-Newman-Keuls tests were used as a 130 method of post hoc comparison (Zar 2010). Additionally, for each temperature 131 and salinity combination, percent $\mathrm{O}_{2}$ regulation and $\mathrm{M}_{\mathrm{O} 2}$ values under different 132 DO conditions were compared by using paired-sample t-tests. A 5\% significance 133 level $(\mathrm{P}=0.05)$ was considered for all statistically tests. Since multiple paired134 sample t-tests were carried out, Bonferroni correction was applied to avoid an 135 increase of statistically significant differences; that is, an experimental P of 0.002 
136 was considered equivalent to a corrected $\mathrm{P}$ of 0.05 . Prior to statistical analyses

137 data were logged $\left(\mathrm{M}_{\mathrm{O} 2}\right)$ or arcsine $\left(\% \mathrm{O}_{2}\right.$ regulation) transformed to homogenize 138 variances.

\section{3. Results}

140 The $\mathrm{M}_{\mathrm{O} 2}$ varied greatly between individuals for each salinity-temperature

141 combination, and there was an oxygen-dependent $\mathrm{M}_{\mathrm{O} 2}$ trend irrespective of the

142 DO (Figure 2). Nevertheless, the degree of oxygen dependence showed some DO

143 related variation: although the shrimp's oxyregulation increased from well-

144 oxygenated water to moderate hypoxia, a decreasing trend was observed under

145 severe hypoxic conditions (Figure 3 and Table 1). We also found an interaction

146 between salinity and temperature that affected the shrimp's oxyregulation

147 capacity: shrimps exposed to brackish water displayed a more temperature-

148 dependent response with lower mean oxyregulation values under higher

149 temperature conditions (Figure 3). Owing to the high $\mathrm{M}_{\mathrm{O} 2}$ variability between

150 individuals, these differences were only statistically significant under moderate

151 and severe hypoxic conditions (Figure 4). Concurrently, the number of individuals

152 (\%) with depressed $\mathrm{M}_{\mathrm{O} 2}$ (negative $\mathrm{O}_{2}$ regulation values) was temperature

153 dependent under severe hypoxia for both salinities, with a higher number of

154 shrimps showing depressed $\mathrm{M}_{\mathrm{O} 2}$ at $30^{\circ} \mathrm{C}$ (Figure 4). Furthermore, at the end of the

155 respiratory experiments ( $\left.\mathrm{DO}<0.3 \mathrm{mg} \mathrm{O}_{2} \mathrm{l}^{-1}\right)$, mortalities of shrimps at $15^{\circ} \mathrm{C}(5 \%$

156 in freshwater and $11 \%$ in brackish water) were lower than at $30^{\circ} \mathrm{C}(79 \%$ and $74 \%$

157 respectively).

158 When the complete DO range (6 to $0.5 \mathrm{mg} \mathrm{l}^{-1}$ ) was considered, the overall

159 degree of oxyregulation varied between $9.6 \%$ at $25^{\circ} \mathrm{C}$ in freshwater and $19.5 \%$ at

$16015^{\circ} \mathrm{C}$ in brackish water, although differences were only statistically significant 
161 between the latter maximum value and the rest (except for shrimps at $25^{\circ} \mathrm{C}$ in

162 brackish water). The percentage of shrimps showing poor $(<10 \%)$ oxyregulation

163 varied between $11.8 \%$ at $15^{\circ} \mathrm{C}$ and $52.2 \%$ at $30^{\circ} \mathrm{C}$ in brackish water, and

164 between $33.3 \%$ and $46.2 \%$ respectively in freshwater (Figure 2).

165 The size-corrected $\mathrm{M}_{\mathrm{O} 2}$ values showed increased respiration rates versus

166 increased temperatures irrespective of the DO and salinity conditions (Figure 3),

167 with the exception of shrimps at 25 and $30^{\circ} \mathrm{C}$ in brackish water, which always had

168 similar $\mathrm{M}_{\mathrm{O} 2}$ values $\left(\mathrm{Q}_{10}\right.$ : 0.8-1.0). Indeed, in well oxygenated water $\left(5 \mathrm{O}_{2} \mathrm{mg} \mathrm{l}^{-1}\right)$,

169 the mean $\mathrm{M}_{\mathrm{O} 2}$ values of a $0.12 \mathrm{~g}$ shrimp resulted in a $\mathrm{Q}_{10}$ of 1.6 between $15^{\circ} \mathrm{C}$ and

$17030^{\circ} \mathrm{C}$ in freshwater and a $\mathrm{Q}_{10}$ of 2.1 between $15^{\circ} \mathrm{C}$ and $25^{\circ} \mathrm{C}$ in brackish water.

171 Under severe hypoxia $\left(1 \mathrm{O}_{2} \mathrm{mg} \mathrm{l}^{-1}\right)$, the mean $\mathrm{M}_{\mathrm{O} 2}$ values resulted in a $\mathrm{Q}_{10}$ of 1.7

172 both between $15^{\circ} \mathrm{C}$ and $30^{\circ} \mathrm{C}$ in freshwater and between $15^{\circ} \mathrm{C}$ and $25^{\circ} \mathrm{C}$ in

173 brackish water (Figure 3). Within each temperature-salinity combination, there

174 was always a significant DO-related decrease in $\mathrm{M}_{\mathrm{O} 2}$ values, although for the

175 same change in $\mathrm{DO}$ the decreases in $\mathrm{M}_{\mathrm{O} 2}$ were smaller between well oxygenated

176 water and moderate hypoxia than between moderate and severe hypoxia (Figure 4

177 and Table 1).

178 4. Discussion

179 The physiological characteristics of organisms generally respond to the

180 environmental changes before the populations and communities do (Barbieri,

181 2007). Due to this early response, the oxygen consumption of organisms could be

182 a useful tool for testing the effects of environmental changes that lead to lower

183 DO levels. Nevertheless, the $\mathrm{M}_{\mathrm{O} 2}$ of aquatic organisms is very variable (Ghiretti, 184 1966; Mangum and Van Winkle, 1973; Vernberg, 1983; Pihl et al., 1991; Salvato

185 et al., 2001) and its effectiveness as a measure of environmental change in 
186 hypoxia scenarios depends on the oxyregulation capacity of the monitored 187 species. As expected for a species which normally lives in well-oxygenated 188 freshwater, Atyaephyra desmarestii has a poorer oxyregulation capacity than 189 species that live in habitats exposed to periodic hypoxic events (Bridges and 190 Brand, 1980; McMahon and Wilkens, 1983; Vernberg, 1983; Salvato et al., 2001;

191 Hicks and Mahon, 2002; Pascual and Drake, 2008; González-Ortegón et al., 192 2010). Moreover, the species shows limited thermal regulation of oxygen uptake 193 within a wide thermal range. These two features suggest that the respiratory 194 response of $A$. desmarestii could be monitored in short term bioassays to test the 195 effects of environmental changes that lead to temperature-related changes in the 196 water oxygenation.

197 The high variability of $\mathrm{M}_{\mathrm{O} 2}$ between Atyaephyra desmarestii individuals is 198 an almost universal feature of ectothermic invertebrates (Ghiretti, 1966; Vernberg, 199 1983; Salvato et al., 2001; Vilas et al., 2006). As this variability is due to both 200 intrinsic and extrinsic factors, it can be partially avoided in future research by 201 selecting a homogeneous (size, gender, season, habitat) group of individuals that 202 best fits the aims of the study. Another potential limitation of this study is that the 203 organisms were kept at $20^{\circ} \mathrm{C}$ and exposed directly (except in $30^{\circ} \mathrm{C}$ experiments) 204 to respiratory chambers at the target temperatures. Thus, the trends reported here 205 should be considered as a measure of the "acute" thermal regulation of $\mathrm{M}_{\mathrm{O} 2}$ and 206 oxy-independence under declining DO; that is, an experimental approach 207 corresponding to the daily short-term changes in temperature and DO which are 208 frequently observed in shallow aquatic habitats of temperate regions (Dalla Via, 209 1985; Arias and Drake, 1987; Pascual and Drake, 2008). However, the respiratory 210 response of $A$. desmarestii obtained in this study might have been different if 211 shrimps had been allowed to acclimatize to the progressively decreasing 
212 temperature, as in the seasonal temperature trend in temperate regions. Long-term

213 acclimatization sometimes improves an organism's tolerance to environmental

214 change (Dalla Via, 1987ab), but unfavourable environmental conditions at or

215 above sublethal physiological limits may also lead to a poorer physiological

216 condition (Leroi et al., 1994; Hicks and Mahon, 2002; Vilas et al., 2009) and

217 consequently lower $\mathrm{M}_{\mathrm{O} 2}$ and oxyregulation abilities. In any case, the

218 aforementioned limitations can be easily overcome by using control replicates in

219 the experimental bioassay design.

220 As the cost of osmotic regulation is usually minimal at isosmotic

221 conditions, shrimps exposed to osmotic stress should show an increase in

222 metabolic rate. The isosmotic point for A. desmarestii is around 17 salinity at

$22320^{\circ} \mathrm{C}$ (unpublished data) and lower oxygen consumption, at least for this

224 temperature, is expected for shrimps in brackish water than in freshwater.

225 However, non-salinity related differences in $\mathrm{M}_{\mathrm{O} 2}$ and respiratory independence

226 were observed at $20^{\circ} \mathrm{C}$ irrespective of the DO. Furthermore, as previously

227 reported for the freshwater shrimp Palaemonetes antennarius (Dalla Via,

228 1987a,b), the respiratory behaviour of A. desmarestii exhibited stronger

229 temperature dependence in brackish water than in freshwater. That is, under

230 hypoxic conditions and at a moderate temperature $\left(15^{\circ} \mathrm{C}\right)$, shrimps from brackish

231 water displayed a significantly higher $\mathrm{M}_{\mathrm{O} 2}$ and oxyregulation than freshwater

232 shrimps; however, these differences were not significant at higher temperatures

$233\left(20-30^{\circ} \mathrm{C}\right)$. A similar decrease in oxygen independence with increasing

234 temperature has been found previously in crustaceans inhabiting brackish and sea

235 water (Taylor, 1976; Bridges and Brand, 1980; Dalla Via, 1985; Daoud et al.,

236 2007; Cerezo et al., 2009). In addition, a change in water temperature from 25 to

$23730^{\circ} \mathrm{C}$ did not increase the $\mathrm{M}_{\mathrm{O} 2}$ of the A. desmarestii in brackish water, which 
238 suggests that temperatures above $25^{\circ} \mathrm{C}$ may represent a physiological limit for this

239 species when exposed to 12 salinity (Van Donk and De Wilde, 1981; Hicks and

240 McMahon, 2002). For freshwater shrimps, however, a temperature above $25^{\circ} \mathrm{C}$

241 seems to represent a physiological limitation only under severe hypoxic

242 conditions. Therefore, in a climate change scenario of increased water temperature

243 and decreased DO (Vaquer-Sunyer and Duarte, 2008, 2011; Conley et al., 2009),

244 the expansion of the brackish water realm could represent an additional handicap

245 for the study species.

246 Aquatic organisms, such as fish and crustaceans, compensate for hypoxia

247 by increasing ventilation (Pihl et al., 1991; Maltby, 1995; Wannamaker and Rice,

248 2000; Hicks and McMahon, 2002), which requires an extra supply of energy.

249 However, at severe hypoxic levels, specimens become less active because they are

250 energy-limited (Das and Stickle, 1994; Hervant et al., 1998; McMahon, 2001).

251 Irrespective of the water temperature, the maximum level of oxyregulation of $A$.

252 desmarestii occurred under moderate hypoxic conditions (Figure 3). After this

253 maximum, increased hypoxia always resulted in decreased oxyregulation.

254 Nevertheless, as previously found for other species (Vaquer-Sunyer and Duarte,

255 2011), oxyregulation began to decrease at a higher DO threshold in warmer water,

256 especially at salinities of 12 . Concurrently, the decreases in $\mathrm{M}_{\mathrm{O} 2}$ were stronger

257 under hypoxic conditions than in well oxygenated water (Table 1). Thus, it seems

258 reasonable to hypothesize that the maximum level of oxyregulation of $A$.

259 desmarestii was a consequence of its behavioural changes (increased ventilation)

260 to compensate for the decrease in DO, whereas the posterior decline in

261 oxyregulation and $\mathrm{M}_{\mathrm{O} 2}$ suggests that further adjustments of the respiratory pump

262 only served to supply its own increased oxygen demand (Bridges and Brand,

263 1980). Under this assumption, A. desmarestii may survive under hypoxic 
264 conditions in brackish water but only at low to moderate temperatures $\left(\mathrm{T} \leq 20^{\circ} \mathrm{C}\right)$;

265 however, in freshwater, its habitual habitat, the oxyregulation capability of $A$.

266 desmarestii seems to be less temperature dependent.

267 Anthropogenic habitat alterations may contribute to placing previously

268 well adapted native species at a competitive disadvantage to invasive species.

269 Under a scenario of increased hypoxic stress in aquatic habitats (eutrophication

270 and climate warming), the ability to maintain the $\mathrm{M}_{\mathrm{O} 2}$ independently of declining

271 DO values may become an essential adaptation of organisms for inhabiting the

272 resulting oxygen-depleted environments (Bridges and Brand, 1980; Diaz and

273 Rosenberg, 1995). Thus, some native species could become more vulnerable to

274 competitive displacement by less oxygen-sensitive invader species (Byers, 2002;

275 Jewett et al., 2005; González-Ortegón et al., 2010). Despite its sensitivity to

276 hypoxia, A. desmarestii, whose original distribution was mainly freshwater

277 habitats from the Mediterranean Basin and the Middle East (García-Múñoz et al., 278 2009), has successfully invaded northwestern Europe (Van den Brink and Van der

279 Velde, 1986; Straka and Špaček, 2009). Global warming could have contributed

280 to this northward displacement of the species because colder waters tend to have

281 higher DO. The wide network of artificial channels for inland shipping that

282 crosses the northwestern European countries has also facilitated the expansion of

283 the species to new river basins.

\section{5. Conclusions}

285 This study evidences that hypoxia does have a significant effect on the oxygen

286 consumption and oxyregulation level of $A$. desmarestii and provides valuable 287 information on the patterns of these responses. Furthermore, the shrimp's 288 sensitivity to the water oxygenation level and its currently wide geographical 
289 distribution suggest that $A$. desmarestii is a good candidate for short-term

290 bioassays that aim to assess the consequences of climate change and pollution

291 events on temperate freshwater ecosystems.

\section{Acknowledgements}

293 This research work was funded by the Spanish Ministry of Science and Innovation through the 294 project Consolider-Ingenio 2010 (CSD2009-00065). Authors would like to thank A. F. Johnson

295 for English correction of the manuscript.

\section{References}

297 Arias, A. M., Drake, P., 1987. Evolución de las condiciones fisicoquímicas y biológicas de un 298 estero y su relación con los ciclos de estancamiento y renovación del agua. Invest. Pesq. 51, 7929995.

Barbieri, E., 2007. Use of Oxygen Consumption and Ammonium Excretion to Evaluate the Sublethal Toxicity of Cadmium and zinc on Litopenaeus schmitti (Burkenroad, 1936, Crustacea). Water. Environ. Res. 79, 641-646.

Bernatis, J.L., Gerstenberger, S.L., McGaw, I.J., 2007. Behavioural responses of the Dungeness crab, Cancer magister, during feeding and digestion in hypoxic conditions. Mar. Biol. 150, 941951 doi: $10.1007 / \mathrm{s} 00227-006-0392-3$

Bridges, C.R., Brand, A.R., 1980. Oxygen consumption and oxygen independence in marine crustaceans. Mar. Ecol. Prog. Ser. 2, 133-141.

Byers, J.E., 2002. Impact of non-indigenous species on natives enhanced by anthropogenic alteration of selection regimes. Oikos 97, 449-458.

Cairns, J., Heath, A.G., Parker, B., 1975 The effects of temperature upon the toxicity of chemicals to aquatic organisms. Hydrobiologia 45, 135-171.

Cerezo Valverde, J., Hernández, M.D., Aguado-Giménez, F., García García, B., 2009. Oxygen consumption in spider crab (Maja brachydactyla): Effect of weight, temperature, sex, feeding and daily light-dark cycle. Aquaculture 298, 131-138.

Conley, D.J., Carstensen, J., Vaquer-Sunyer, R., Duarte, C.M., 2009. Ecosystems thresholds with hypoxia. Hydrobiologia 629, 21-29. doi:10.1007/s10750-009-9764-2

Dalla Via, G.J., 1985. Oxygen consumption and temperature change in the shrimp Palaemon elegans. Mar. Ecol. Prog. Ser. 26, 199-202.

Dalla Via, G.J., 1987a. Salinity responses in brackish water populations of the freshwater shrimp Palaemonetes antennarius - I. Oxygen consumption. Comp. Biochem. Physiol. 87A, 471-478.

Dalla Via, G.J., 1987b. Effects of salinity and temperature on oxygen consumption in a freshwater population of Palaemonetes antennarius. Comp. Biochem. Physiol. 88A, 299-305.

Daoud, D., Chabot, D., Audet, C., Lambert, Y., 2007. Temperature induced variation in oxygen consumption of juvenile and adult stages of the northern shrimp, Pandalus borealis. J. Exp. Mar. Biol. Ecol. 347, 30-40.

Das, T., Stickle, W.B., 1994. Detection and avoidance of hypoxic water by juvenile Callinectes sapidus and C. similis. Mar. Biol. 120, 593-600. doi: 10.1007/BF00350080 
Diaz, R.J., Breitburg, D.L., 2009. The hypoxic environment, in: Richards, J.G., Farrell, A.P.,

Diaz, R.J., Rosenberg, R., 1995. Marine benthic hypoxia: a review of its ecological effects and the behavioural responses of benthic macrofauna. Oceanogr. Mar. Biol. 33, 245-303.

Fränzle, O., 2006. Complex bioindication and environmental stress assessment. Ecol. Indic. 6, $114-136$.

García-Berthou, E., Moreno-Amich, R., 2000. Food of introduced pumpkinseed sunfish: ontogenic diet shift and seasonal variation. J. Fish. Biol. 57, 29-40.

García-Muñoz, J.E., Rodríguez, A., García Raso, J.E., Cuesta, J.A., 2009. Genetic evidence for cryptic speciation in the freshwater shrimp genus Atyaephyra de Brito Capello (Crustacea, Decapoda, Atyidae). Zootaxa 2025, 32-42.

Ghiretti, F., 1966. Respiration, in: Wilbur, K.M., Yonge, C.M. (Eds.), Physiology of Mollusca 2. Academic Press, New York and London, pp. 175-208.

González-Ortegón, E., Cuesta, J.A., Pascual, E., Drake, P., 2010. Assessment of the interaction between the white shrimp, Palaemon longirostris, and the exotic oriental shrimp, Palaemon macrodactylus, in a European estuary (SW Spain). Biol. Invas. 12, 1731-1745. doi:10.1007/ s10530-009-9585-2

Hervant, F., Mathieu, J., Messana, G., 1998. Oxygen Consumption and Ventilation in Declining Oxygen Tension and Posthypoxic Recovery in Epigean and Hypogean Crustaceans. J. Crust. Biol. $18,717-727$.

Hicks, D.W., McMahon, R.F., 2002. Temperature and relative humidity effects on water loss and emersion tolerance of Perna perna (L.) (Bivalvia: Mytilidae) from the Gulf of Mexico. Bull. Mar. Sci. $72,135-150$.

Janssens de Bisthoven, L., Gerhardt, A., Guhr, K., Soares, A.M.V.M., 2006. Behavioral changes and acute toxicity to the freshwater shrimp Atyaephyra desmarestii Millet (Decapoda: Natantia) from exposure to acid mine drainage. Ecotoxicology 15, 215-227.

Jewett, E.B., Hines, A.H., Ruiz, G.M., 2005. Epifaunal disturbance by periodic low levels of dissolved oxygen: native vs. invasive species response. Mar. Ecol. Prog. Ser. 304, 31-44.

Leroi, A.M., Bennett, A.F., Lenski, R.E., 1994. Temperature acclimation and competitive fitness: an experimental test of the beneficial acclimation assumption. Proc. Natl. Acad. Sci. USA 91, 1917-21.

Maltby, L., 1995. Sensitivity of the crustacean Gammarus pulex (L.) and Asellus aquaticus (L.) to short-term exposure to hypoxia and unionized ammonia: observation and possible mechanisms. Wat. Res. 29, 781-787.

Mangum, C., Van Winkle, W., 1973. Responses of aquatic invertebrates to declining oxygen conditions. Am. Zool. 13, 529-541.

McMahon, B.R., 2001. Respiratory and circulatory compensation to hypoxia in crustaceans. Resp. Physiol. 128, 349-364.

McMahon, B.R., Wilkens, J.L., 1983. Ventilation, perfusion and oxygen uptake, in: Mantel, L.H. (Ed.), The Biology of Crustacea, vol. 5, Internal Anatomy and Physiological Regulation. Academic Press, New York, pp. 289-372.

Paschke, K., Cumillaf, J.P., Loyola, S., Gebauer, P., Urbina, M., Chimal, M.E., Pascual, C., Rosas, C., 2010. Effect of dissolved oxygen level on respiratory metabolism, nutritional physiology, and 
immune condition of southern king crab Lithodes santolla (Molina, 1782) (Decapoda, Lithodidae).

Pascual, E., Drake, P., 2008. Physiological and Behavioral Responses of the Mud Snails Hydrobia glyca and Hydrobia ulvae to Extreme Water Temperatures and Salinities: Implications for Their Spatial Distribution within a System of Temperate Lagoons. Physiol. Biochem. Zool. 81, 594-604.

Pestana, J.L.T., Ré, A., Nogueira, A.J.A., Soares, A.M.V.M., 2007. Effects of Cadmium and Zinc on the feeding behaviour of two freshwater crustaceans: Atyaephyra desmarestii (Decapoda) and Echinogammarus meridionalis (Amphipoda). Chemosphere 68, 1556-1562.

Phil, L., Baden, S.P., Diaz, R.J., 1991. Effects of periodic hypoxia on distribution of demersal fish and crustaceans. Mar. Biol. 108, 349-360.

Rakocinski C. F., 2012. Evaluating macrobenthic process indicators in relation to organic enrichment and hypoxia. Ecol. Indic.13, 1-12.

Salvato, B., Cuomo, V., Di Muro, P., Beltramini, M., 2001. Effects of environmental parameters on the oxygen consumption of four marine invertebrates: a comparative factorial study. Mar. Biol. 138, 659-668 doi:10.1007/s002270000501

Shimps, E.L., Rice, J.A., Osborne, J.A., 2005. Hypoxia tolerance in two juvenile estuarydependent fishes. J. Exp. Mar. Biol. Ecol. 325, 146-162.

Straka, M., Špaček, J., 2009. First record of alien crustaceans Atyaephyra desmarestii (Millet, 1831) and Jaera istri Veuille, 1979 from the Czech Republic. Aquat. Invas. 4, 397-399.

Taylor, E.W., 1976. The respiratory responses of Carcinus maenas to declining oxygen tension. J. Exp. Biol. 65, 309-322.

Van Den Brink, F.W.B., Van Der Velde, G., 1986. Observations on the seasonal and yearly occurence and the distribution of Atyaephyra desmarestii (Millet, 1831) (Crustacea, Decapoda, Natantia) in the Netherlands. Hydrobiol. Bull. 19, 2193-2198.

Van Donk, E., De Wilde, A.W.J., 1981. Oxygen consumption and motile activity of the brown shrimp Crangon crangon related to temperature and body size. Neth. J. Sea Res. 15, 54-64.

Vaquer-Sunyer, R., Duarte, C.M., 2008. Thresholds of hypoxia for marine biodiversity. Proc. Natl. Acad. Sci. USA 105, 15452-15457.

Vaquer-Sunyer, R., Duarte, C.M., 2011. Temperature effects on oxygen thresholds for hypoxia in marine benthic organisms. Glob. Change Biol. 17, 1788-1797.

Verberg, F.J., 1983. Respiratory adaptations, in: Vernberg, F.J., Vernberg, W.B. (Eds.), The biology of Crustacea Vol. 8: Environmental Adaptations. Academic Press, New York, pp. 1-42.

Vilas, C., Drake, P., Pascual, E., 2006. Oxygen consumption and osmoregulatory capacity in Neomysis integer reduce competition for resources among mysid shrimp in a temperate estuary. Physiol. Biochem. Zool. 79, 866-877.

Vilas, C., Drake, P., Pascual, E., 2009. Inter- and intra-specific differences in euryhalinity determine the spatial distribution of mysids in a temperate European estuary. J. Exp. Mar. Biol. Ecol. 369, 165-176.

Wannamaker, C.M., Rice, J.A., 2000. Effects of hypoxia on movements and behavior of selected estuarine organisms from the southeastern United States. J. Exp. Mar. Biol. Ecol. 249, 145-163.

Zar, J.H., 2010. Biostatistical Analysis, 2nd edn. Prentice-Hall, Englewood Cliffs, New Jersey. 
462 Fig. 1 Graphical examples of experimental data smoothing (third order polynomial curve fitting)

463 and oxyregulation measures of $A$. desmarestii (differences between experimental $\mathrm{M}_{\mathrm{O} 2}$ values and

464 those expected in a total osmoconform shrimps)

466 Fig. 2 Relative specific oxygen consumption rates of $A$. desmarestii shrimps exposed to different combinations of temperature and salinity versus oxygen concentration inside the respiratory chamber. Figures in the right bottom corner of each plot represent mean $( \pm$ SE) oxyregulation value and percent of shrimps with poor $(<10 \%)$ oxyregulation; lowercase letters, mean statistically

472 Fig. 3 For each temperature-salinity combination, mean values of shrimps' oxygen independence versus oxygen concentration inside the respiratory chamber. Vertical lines indicate oxygen concentrations at which the respiratory variables were statistically tested

Fig. 4 Box plots of specific oxygen consumption rates (above), oxy-independence (middle) and percent of shrimps, A. desmarestii, with depressed oxygen consumption (bottom) when they were exposed to different temperature, salinity and oxygen concentration inside the respiratory chamber. 
Table 1 For each temperature-salinity combination, changes in specific oxygen consumption rates $\left(\mathrm{M}_{\mathrm{O} 2}\right)$ and oxy-independence (mean $\pm \mathrm{SE}$ ) of a $0.12 \mathrm{~g}$ wet weight $A$. desmarestii when exposed to different $\mathrm{Cw}_{\mathrm{O} 2}$ conditions

\begin{tabular}{|c|c|c|c|c|}
\hline \multirow[b]{2}{*}{ Temp.-Salinity } & \multicolumn{2}{|c|}{ Decrease in $\mathrm{M}_{\mathrm{O} 2}$} & \multicolumn{2}{|c|}{ Change in $\%$ oxy-independence } \\
\hline & 5 to $3 \mathrm{mgl}^{-1} \mathrm{O}_{2}$ & 3 to $1 \mathrm{mgl}^{-1} \mathrm{O}_{2}$ & 5 to $3 \mathrm{mgl}^{-1} \mathrm{O}_{2}$ & 3 to $1 \mathrm{mgl}^{-1} \mathrm{O}_{2}$ \\
\hline $15^{\circ} \mathrm{C}-0.3$ & $127.8 \pm 9.1 *$ & $195.4 \pm 11.3 *$ & $9.2 \pm 1.2 *$ & $-4.5 \pm 2.0$ \\
\hline $20^{\circ} \mathrm{C}-0.3$ & $154.7 \pm 15.3 *$ & $254.6 \pm 114.6 *$ & $10.0 \pm 1.1 *$ & $-6.5 \pm 1.1 *$ \\
\hline $25^{\circ} \mathrm{C}-0.3$ & $247.5 \pm 12.9 *$ & $364.9 \pm 14.4 *$ & $7.5 \pm 1.0 *$ & $-5.9 \pm 1.2 *$ \\
\hline $30^{\circ} \mathrm{C}-0.3$ & $282.6 \pm 24.7 *$ & $488.5 \pm 22.3 *$ & $9.8 \pm 1.4 *$ & $-8.7 \pm 1.8 *$ \\
\hline $15^{\circ} \mathrm{C}-12$ & $93.9 \pm 10.7 *$ & $191.5 \pm 16.9 *$ & $14.8 \pm 1.2 *$ & $-1.6 \pm 2.6$ \\
\hline $20{ }^{\circ} \mathrm{C}-12$ & $139.7 \pm 15.6 *$ & $263.6 \pm 20.5 *$ & $13.0 \pm 1.1 *$ & $-8.3 \pm 2.9$ \\
\hline $25^{\circ} \mathrm{C}-12$ & $241.6 \pm 22.8 *$ & $428.1 \pm 20.5 *$ & $10.5 \pm 1.4 *$ & $-6.7 \pm 2.4 *$ \\
\hline $30^{\circ} \mathrm{C}-12$ & $228.5 \pm 22.0 *$ & $445.9 \pm 29.5 *$ & $8.7 \pm 1.3 *$ & $-7.7 \pm 2.9$ \\
\hline
\end{tabular}



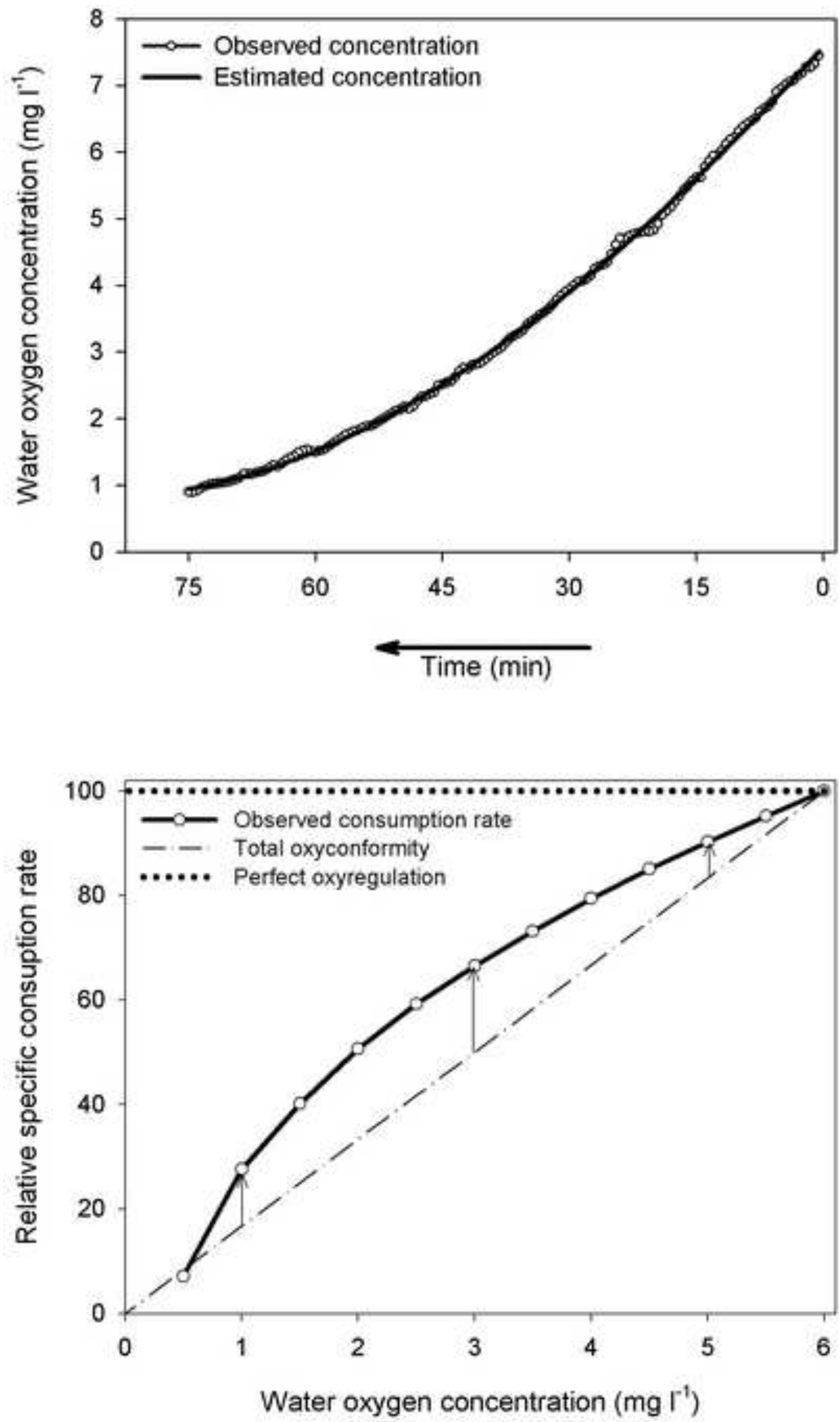
$S=0.3$
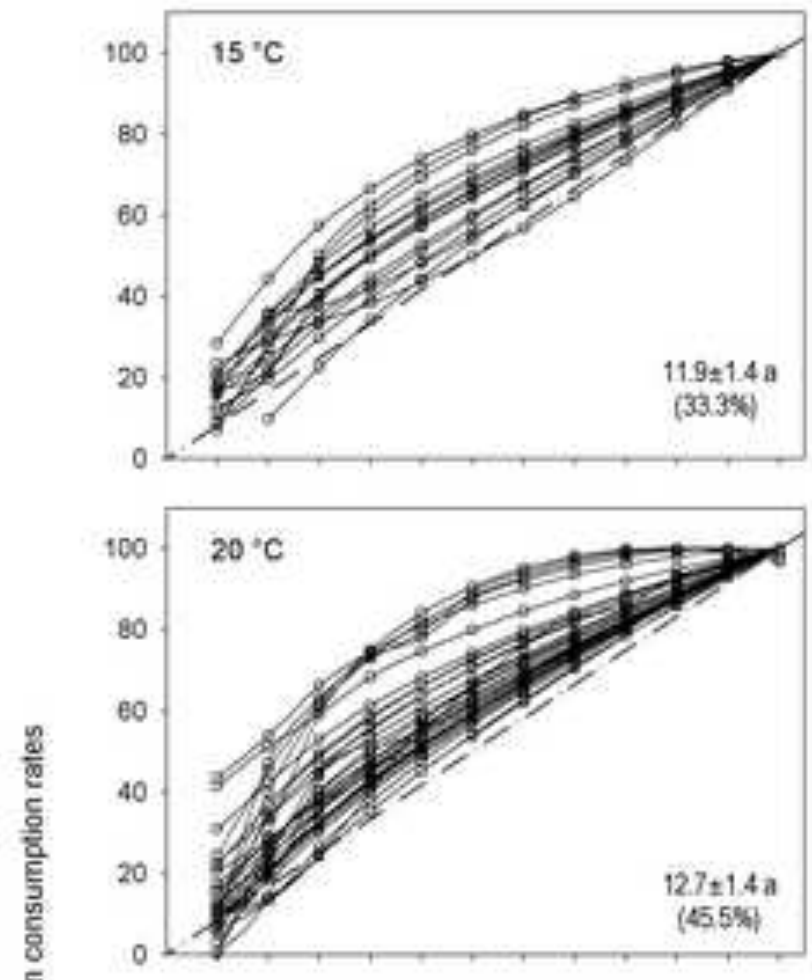

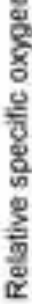
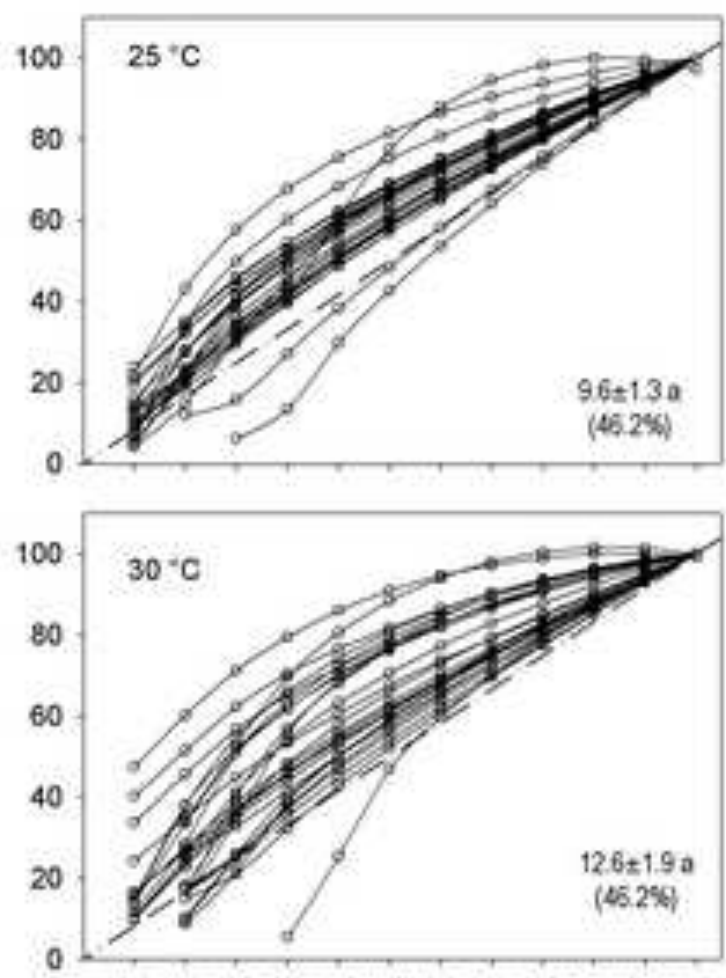

$0.51 .0 \quad 15202530 \quad 3.540 \quad 455.05550$
$S=12$
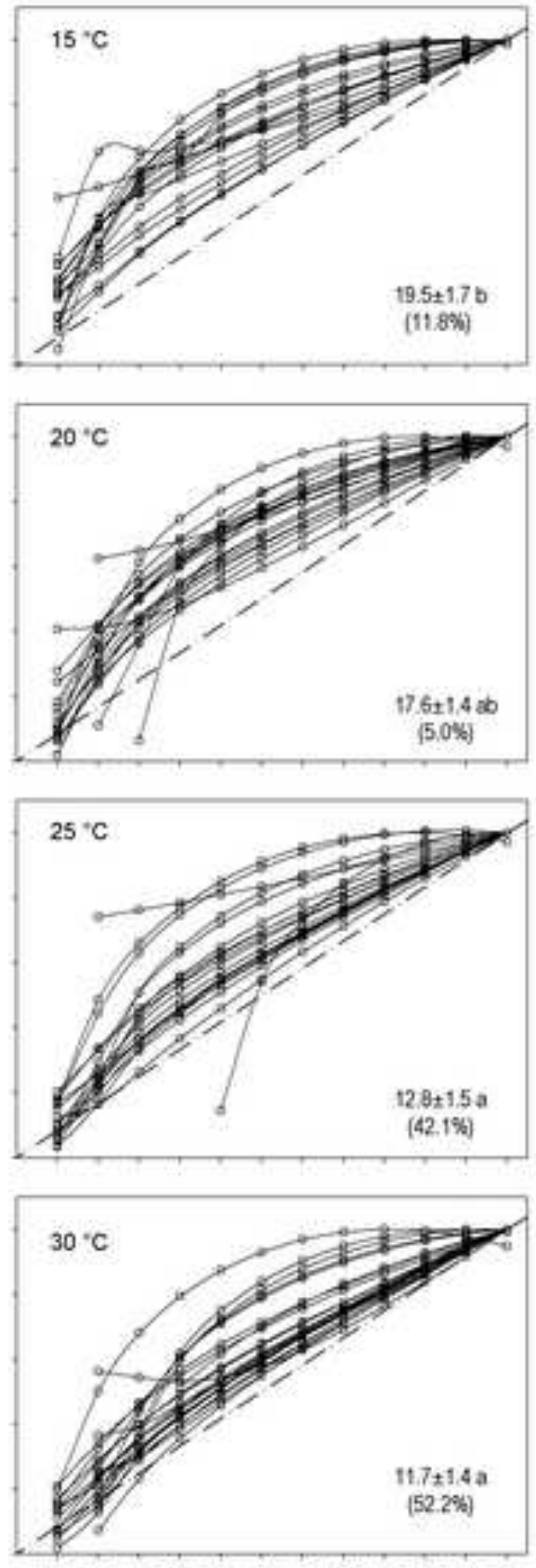

$0.510 \quad 15202530 \quad 3540 \quad 4550 \quad 55 \quad 60$

Water oxygen concentration (mg f') 


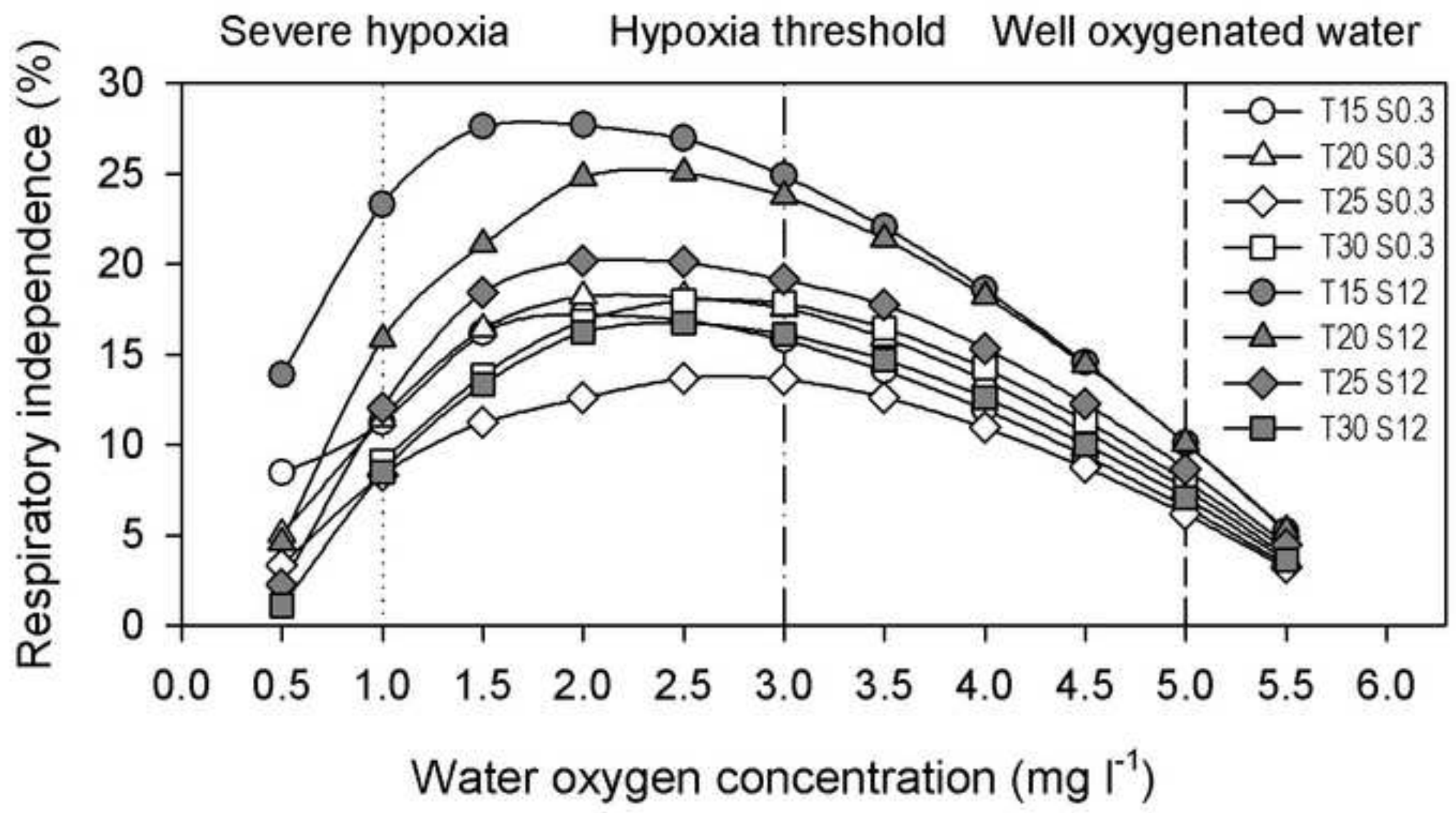


Water oxygen concentration
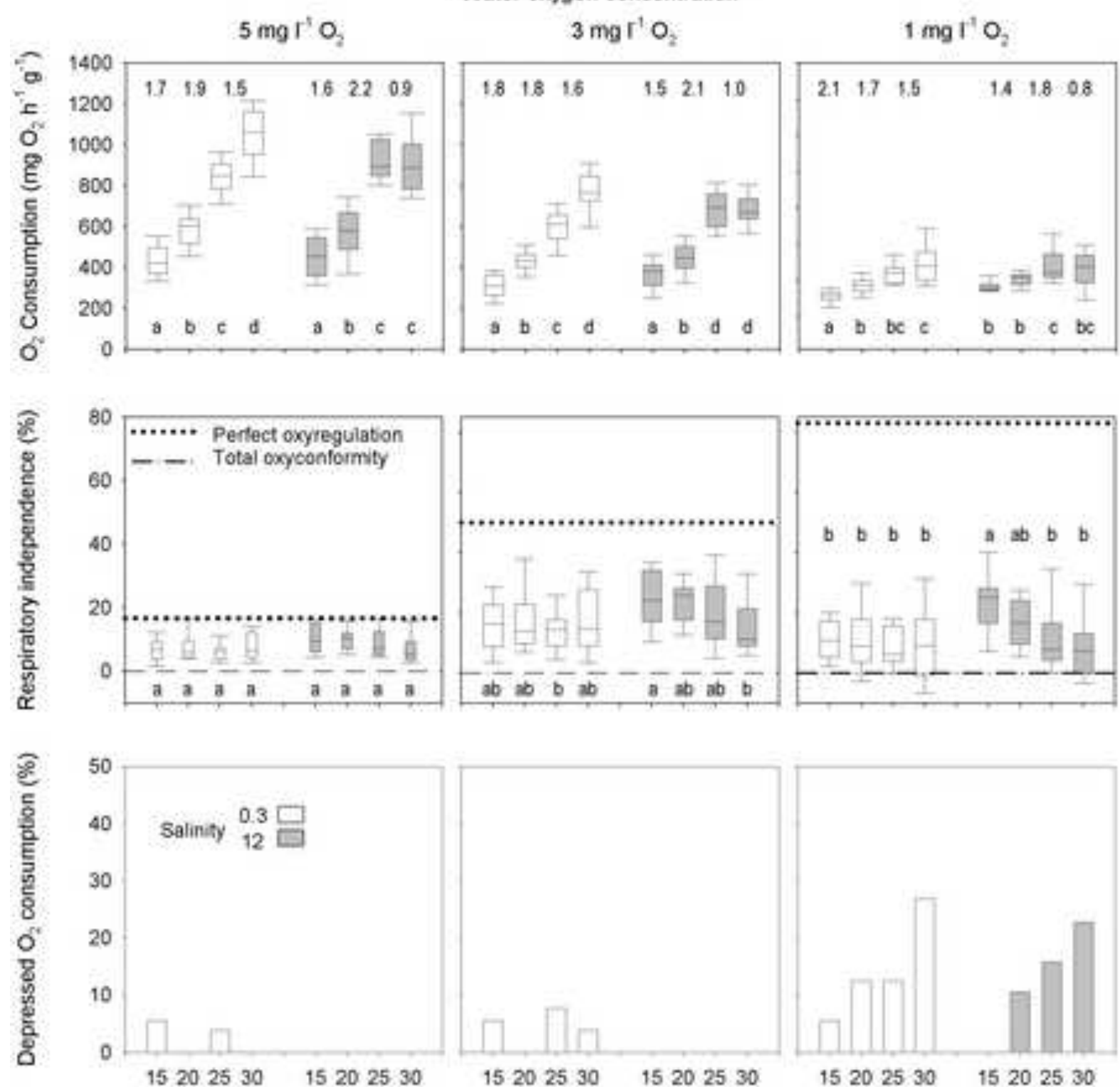

$15202530 \quad 15202530 \quad 15202530 \quad 15202530$ Temperature ( $\left.{ }^{\circ} \mathrm{C}\right)$ 